\title{
In vitro staining of intramuscular nerve endings ${ }^{1}$
}

\author{
R. H. EVANS, J. HAYNES, C. J. MORRIS, AND A. L. WOOLF \\ From the Midland Centre for Neurosurgery and Neurology, Smethwick, Worcestershire
}

SUMMARY A method is described for vital staining of the human intramuscular nerve endings after the muscle biopsy has been removed form the patient. The muscle is transferred from the site of operation to the laboratory in oxygenated physiological saline. Methylene blue solution $(0.015 \%)$ is injected into the muscle strip, and development of the stain can be observed under the microscope after exposure of the muscle to air. Permanent squash preparations can be made of the stained muscle and these are identical in appearance to muscles stained by injection of methylene blue in vivo.

Coërs (1952) introduced vital staining of the intramuscular nervous system in human muscle biopsies by injecting methylene blue solution into the muscle in situ at operation. Reske-Nielsen, Harmsen, and Hejgaard (1969) have introduced a modified technique which still involves injection of methylene blue into the muscle in situ. We have recently abandoned this method, because we have found that just as good a result can be obtained by using muscle removed from the patient before applying the staining solution.

\section{MATERIALS AND METHODS}

Methylene blue solution $0.015 \%$ in $0.89 \% \mathrm{NaCl}$. Physiological saline. Concentrations in $\mathrm{g} / \mathrm{l} . \mathrm{NaCl} 8.90 ; \mathrm{KCl}$ $0.429 ; \mathrm{NaHCO}_{3} 1.00 \mathrm{~g} ; \mathrm{CaCl}_{2} 0.222 \mathrm{~g} ; \mathrm{MgCl}_{2} .5 \mathrm{H}_{2} \mathrm{O}$ $0.203 \mathrm{~g}$; glucose $2.00 \mathrm{~g}$. Ammonium molybdate. Saturated solution in distilled water, filtered before use.

The muscle specimen containing the innervated zone, usually palmaris longus, is cut out by the surgeon under local anaesthesia (Coërs and Woolf, 1959). The strip of muscle, about $3 \mathrm{~cm}$ long by $0.5 \mathrm{~cm}$ diameter, is then placed in a vessel containing saline for transportation to the laboratory. The saline is oxygenated with $96 \% \mathrm{O}_{2} / 4 \%$ $\mathrm{CO}_{2}$ mixture by means of a glass tube connected to a cylinder, capacity $12 \mathrm{cu}$. ft.

In the laboratory up to 60 minutes after the biopsy, the strip of muscle is pinned at both ends onto a cork board. The methylene blue solution is injected by inserting the needle of the syringe containing the solution into one of the cut ends of the muscle strip and injecting as the syringe is withdrawn. The needle used for the injection must be long and thin; we used 26 gauge $\times 2$ in. $(5 \mathrm{~cm})$. About six injections into the muscle strip are

${ }^{1}$ In receipt of grants from the National Fund for Research into Crippling Diseases, the Medical Research Council and the Muscular Dystrophy Group of Great Britain. made, using a total of 10 to $20 \mathrm{ml}$. methylene blue solution.

Five minutes after injection of the dye the blue strip of muscle is subdivided longitudinally into strips 2 to 3 $\mathrm{mm}$ wide using a scalpel blade. The strips are exposed to the air on a saline moistened gauze at room temperature for 30 to 60 minutes, to allow oxidation of the methylene blue. At this stage the staining can be observed by placing the muscle strips between two slides under $\times 100$ magnification, and the muscle can be cut to include the innervation zone only. The muscle must not be squeezed excessively during this examination. If at this stage staining has not taken place in any of the samples, more methylene blue can be injected.

When staining is seen to be complete, the small pieces of muscle are immersed in the ammonium molybdate solution overnight at room temperature and then washed in running tap water for one hour. The muscle pieces are then pressed between slides to flatten them as described by Woolf (1962), the flattened pieces are dehydrated in alcohol, cleared in xylene, and permanently mounted.

\section{RESULTS}

Figure 1 shows a muscle specimen stained by the original method, injecting the methylene blue in vivo, and Fig. 2 shows a specimen stained by the method described above.

\section{CONCLUSION}

Forty-six muscle biopsies have been stained using this method and this has simplified the biopsy procedure considerably. Because it is not necessary to inject the dye during operation, the degree of staining does not depend on familiarity of the surgeon with the technique. After removal of the biopsy specimen, the application of the methylene blue solution can be varied, so producing the required intensity of staining. 


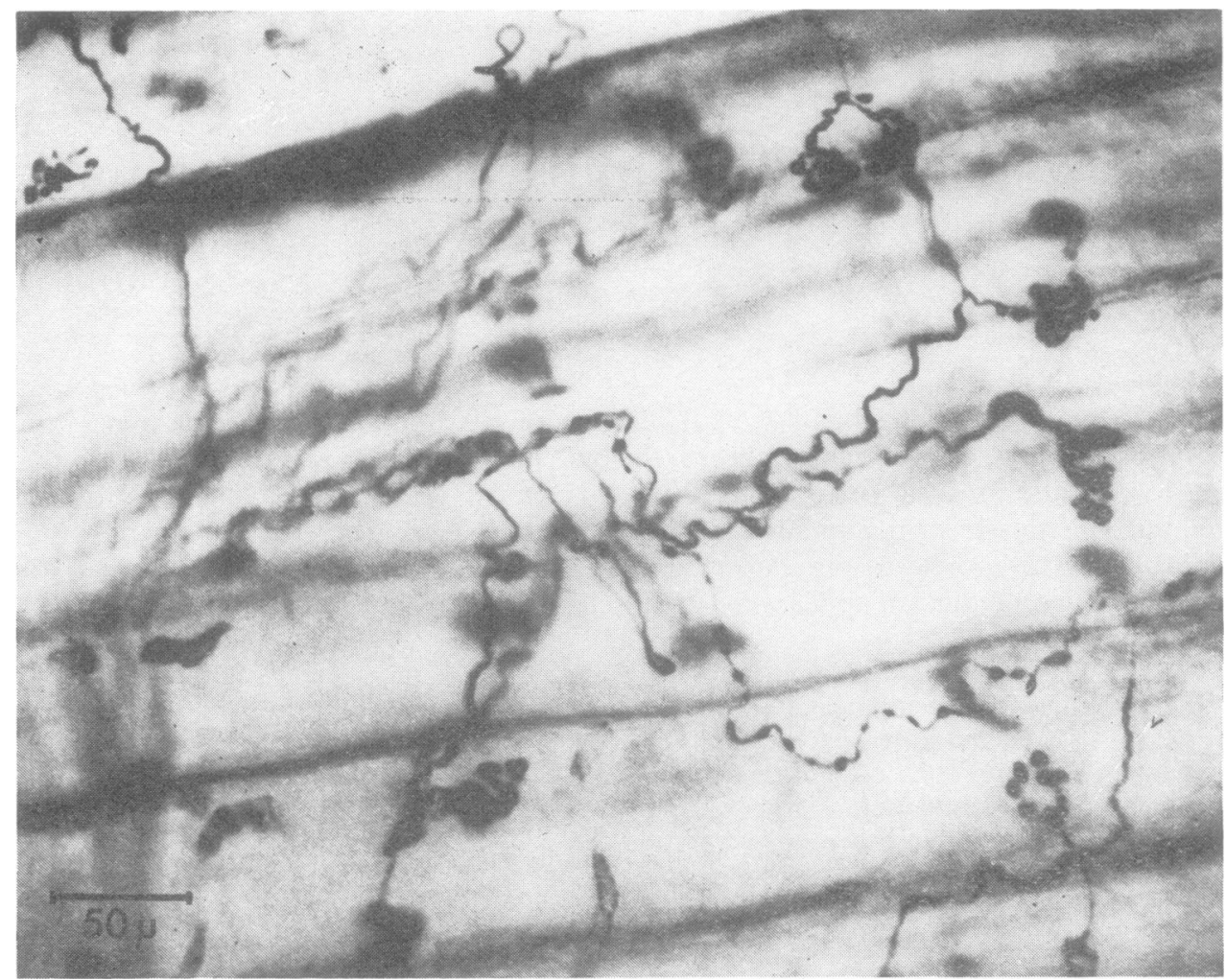

FIG. 1. Squash preparation of palmaris longus showing intramuscular nerve endings stained by the original technique of injecting methylene blue in vivo. Calibration $50 \mu$.

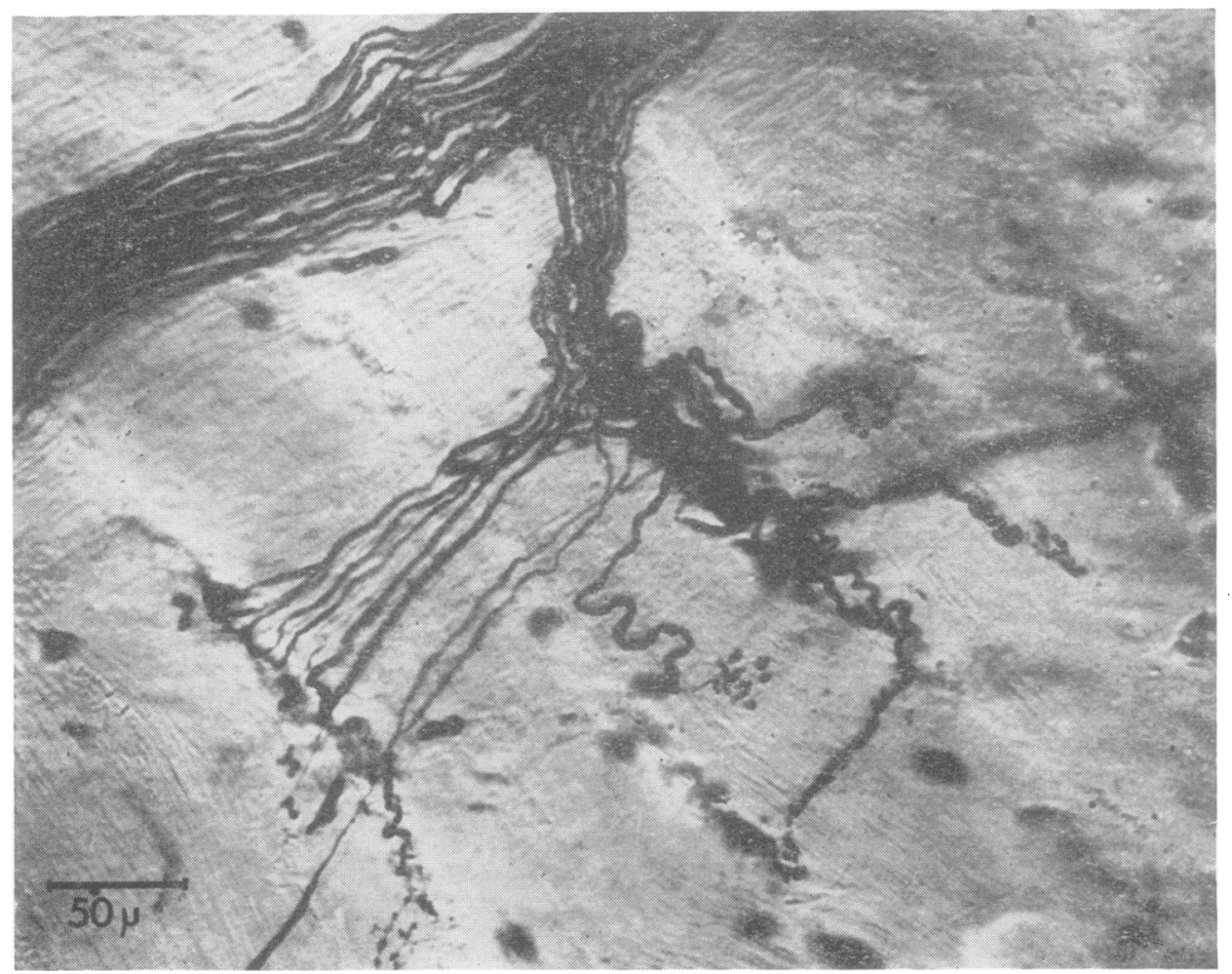

FIG. 2. Squash preparation of palmaris longus showing intramuscular nerve endings stained by injection of methylene blue in vitro. Calibration $50 \mu$. 


\section{ADDENDUM}

The authors sincerely regret the death on 3 March 1970 , of Dr. A. L. Woolf, who contributed so much to present knowledge of the pathology of intramuscular nerve endings. Please address reprint requests to Dr. R. H. Evans, Midland Centre for Neurosurgery and Neurology, Holly Lane, Smethwick, Warley, Worcestershire.
REFERENCES

Coërs, C. (1952). The vital staining of muscle biopsies with methylene blue. J. Neurol. Neurosurg. Psychiat., 15, 211-215.

Coërs, C., and Woolf, A. L. (1959). The Innervation of Muscle A Biopsy Study. p. 6. Blackwell: London.

Reske-Nielsen, E., Harmsen, A., and Højgaard, J. (1969). Modified technique of muscle biopsy. Acta Path. Microbiol. Scand., 77, 578-588.

Woolf, A. L. (1962). Modern Trends in Neurology, Vol. 3, edited by D. Williams. p. 20. Butterworth: London. 